2017-02-16

\title{
Voluntary and Involuntary Imagery in Social Anxiety
}

\author{
Homer, Sophie
}

http://hdl.handle.net/10026.1/8516

10.1017/S1352465817000017

Behavioural and Cognitive Psychotherapy

Cambridge University Press (CUP)

All content in PEARL is protected by copyright law. Author manuscripts are made available in accordance with publisher policies. Please cite only the published version using the details provided on the item record or document. In the absence of an open licence (e.g. Creative Commons), permissions for further reuse of content should be sought from the publisher or author. 


\title{
Voluntary and involuntary imagery in social anxiety
}

\begin{abstract}
Background: Negative mental imagery is ubiquitous in cognitive models of social anxiety and in the social anxiety literature. Previous research has shown that it is causal of increased anxiety, lower social performance ratings and lower implicit selfesteem. Despite its prevalence, few studies have investigated this imagery directly.
\end{abstract}

Aims: This study aimed to provide an in-depth analysis of the phenomenology of negative imagery experienced by socially anxious individuals, and to compare recurrent and intrusive images to images deliberately generated by participants during the study.

Method: Thirty-eight undergraduate students screened to be above average in social anxiety scores completed a computerised imagery questionnaire adapted from previous qualitative work.

Results: Thematic analyses revealed four major image themes for intrusive images and three for deliberately generated images including interacting with others and anxiety symptoms. Most intrusive images were based on negative episodic memories and were experienced at least fortnightly. Images were primarily visual, auditory and somatic but could involve any sensory modality. Depression anxiety stress scale (DASS-21) scores were higher in participants who experienced intrusive imagery and increased with the frequency of intrusions. Emotionality was generally higher in intrusive images than generated images. 
Conclusions: The phenomenology of negative imagery experienced by socially anxious individuals is idiosyncratic and may be inherently different from images generated for use in experimental research. Theoretical and clinical implications are discussed. 
"When these intrusive thoughts appear, they often take place in real life too." 1

\section{Introduction}

Recurrent and intrusive mental imagery features invariably in cognitive models of social anxiety (Hirsch \& Holmes, 2007; Ng, Abbott \& Hunt, 2014). Clark \& Wells (1995) proposed that perceived social inadequacy conducive to fear of negative appraisal is reinforced by heightened self-monitoring and focus on physiological anxiety symptoms during social interaction. Individuals use this information to form biased self-representations from which they infer how they are evaluated by others (Hackmann, Surawy \& Clark, 1998). In Rapee and Heimberg's (1997) model, a baseline self-representation is continually updated based on environmental cues and (overestimated) physiological anxiety symptoms. Comparably, Hofmann (2007) models social anxiety as a vicious cycle: apprehension of social situations is fuelled by high social performance standards and heightened focus on negative selfperception, often in the form of imagery, leads to rumination and reinforcement of fear.

The consensus within these models is that the negative imagery experienced by socially anxious individuals features the self from an observer (third person, or 'outsider') perspective, rather than an image of others from a field (first person, one's own) perspective (Hirsch \& Holmes, 2007; Ng et al., 2014): as though looking at oneself through the eyes of another (Clark \& Wells, 1995; Hofmann, 2007; Rapee and Heimberg, 1997). Studies have confirmed higher instances of the observer perspective in socially anxious individuals recalling high anxiety social situations and negative mental imagery (Coles, Turk, Heimberg \& Fresco, 2001; Hackmann et al.,

1 Quote from a participant in this study. 
1998; Wells, Clark \& Ahmad, 1998; Wells \& Papageorgiou, 1999). However, the primacy of the observer perspective is rendered somewhat contentious by more recent studies: Moscovitch, Gavric, Merrifield, Bielak, \& Moscovitch (2011) found highly socially anxious participants to be no more likely to retrieve negative imagery from the observer perspective than from the field perspective, and the majority of Homer, Deeprose and Andrade's (2016) participants generated public speaking anxiety-images in the field perspective.

Experimental manipulations have shown that negative imagery is a causal factor in social performance. Socially anxious participants visualising negative rather than neutral self-imagery when conversing with a partner report increased anxiety and safety behaviours, and are rated as appearing more anxious by their interlocutors and independent observers (Hirsch, Clark, Mathews \& Williams, 2003; Hirsch, Meynen \& Clark, 2004). This effect was replicated in lectures given by confident public speakers (Hirsch, Mathews, Clark, Williams \& Morrison, 2006), providing compelling evidence that negative imagery 'contaminates' social interaction (Hirsch et al., 2004), and a recent study by Homer et al. (2016) suggests that negative public speaking images also contaminate imagined prospective public speaking experiences. Additionally, visualising negative self-imagery has been shown to have an adverse impact on self-esteem and resilience to social threat (Hulme, Hirsch \& Stopa, 2012). Accordingly, several methods of imagery-focused intervention are emerging including image rescripting within social anxiety (Nilsson, Lundh, \& Viborg, 2012; Wild, Hackmann \& Clark, 2008), and working memory interference techniques (Homer, et al., 2016; Kearns \& Engelhard, 2015; see also van den Hout \& Engelhard, 2012) based on the active eye-movement component of EMDR as typically used in posttraumatic stress disorder (see Lee \& Cuijpers, 2013). 
Despite the cardinal role of imagery in social anxiety (Hirsch \& Holmes, 2007) and growing body of experimental research, there have been relatively few qualitative investigations into its nature and content. Hackmann et al. (1998) first investigated the imagery experienced by individuals meeting diagnostic criteria for social anxiety disorder, who were more likely than non-anxious controls to experience intrusive negative imagery during social situations such as seeing oneself blushing, sweating or shaking. In a follow-up study, Hackmann, Clark and McManus (2000) conducted semi-structured interviews with 22 socially anxious participants, all of whom recurrently and intrusively experienced salient memories of a negative social interaction they believed to have caused or directly preceded their social anxiety. These images were primarily visual with accompanying bodily sensations or auditory elements and the majority originated from a specific episodic memory. Memory themes included being criticised; others critically acknowledging anxiety symptoms; experiencing anxiety symptoms and worrying others will notice; feeling selfconscious as a result of past criticism; feeling bad about self-image; and disinterest from others. Homer et al. (2016) interviewed 20 individuals screened to be anxious of public speaking. Of these participants, 17 (85\%) experienced negative imagery during the interview, and $18(90 \%)$ identified a clear visual image that represented their anxiety (e.g. seeing oneself "red faced and shaking"). Image themes included being the centre of attention, looking anxious, making a mistake, being judged by the audience and anticipatory anxiety. Experimental paradigms often use Hackmann et al.'s (2000) interview template or similar to generate negative imagery (see $\mathrm{Ng}$ et al., 2014), but the content and nature of this imagery is seldom reported.

Despite current interest in negative imagery and associated interventions, a relatively small number of studies have investigated its phenomenology in socially anxious 
samples. Though the importance of assessing idiosyncratic rather than standardised imagery is recognised (e.g. Sansen, Iffland \& Neuner, 2015), no studies have facilitated comparison between intrusive images, which come to mind involuntarily as part of the day to day experience of individuals with social anxiety, to the imagery deliberately generated in laboratory studies. In experimental paradigms, imagery is typically generated by asking the participant to recall a high anxiety social situation with prompts from the experimenter as required. Voluntary and involuntary memories are considered independent (Brewin \& Holmes, 2003; Conway \& Pleydell-Pearce, 2000; Ehlers \& Clark, 2000), and so there may be intrinsic differences in voluntarily recalled and involuntarily experienced social anxiety images, despite both types of image being personally relevant and idiosyncratic. This study therefore sought to qualitatively explore examples of both intrusive and deliberately generated images to update and further the findings of Hackmann et al. (1998) and Hackmann et al. (2000), and to provide a preliminary reference point for future experimental and theoretical work.

The study used a sub-clinical sample of undergraduate students screened to be at least one standard deviation above average on the Social Interaction Anxiety Scale (SIAS; Mattick \& Clarke, 1998) as per Hulme, Hirsch and Stopa (2012). Participants completed a computerised imagery questionnaire based on previous work by Homer et al. (2016) initially adapted from the semi-structured interviews conducted by Hackmann et al. (2000). Our primary exploratory research question was: what do intrusive social anxiety images tend to involve? Additionally, several predictions emerged from our review of the existing literature:

1) Imagery relating to social situations would be experienced regularly and intrusively 
2) Imagery would reflect specific episodic memories

3) Imagery would be primarily visual

4) Intrusive imagery would be associated with higher levels of negative emotionality than generated imagery

5) Imagery would primarily consist of negative self-representations from an observer perspective

\section{Method}

\section{Participants}

Thirty-eight Plymouth University undergraduates screened for above average social anxiety participated for course credit or payment $(£ 6)$, mean age $=21, S D=4.18$, age range $=18-38,27$ females. Seven participants $(18.4 \%)$ disclosed having been diagnosed with or received treatment for an anxiety disorder, two participants (5.3\%) indicated uncertainty and three participants $(7.9 \%)$ declined to respond to this question.

\section{Materials and Measures}

Screening measure: Participants were screened using the Social Interaction Anxiety Scale (SIAS) (Mattick \& Clark, 1998). The SIAS consists of 19 items including "When mixing socially I am uncomfortable". Mattick \& Clark (1998) report high internal validity, Cronbach's $\alpha=0.93$, and high construct validity with the State-Trait Anxiety Inventory - Trait (STAI-T), $r=.58, p<.001$, and the Fear of Negative Evaluation scale (FNES), $r=.66, p<.001$. Participants responded on a 5 -point Likert scale 
scored 0-4 (never/almost never; not usually; sometimes; usually; always/almost always), providing scores between 0 and 76. Mattick \& Clark (1998) report an undergraduate mean of 19, SD = 10.1. As per Hulme, Hirsch \& Stopa (2012), students scoring at least one SD above average ( $\geq 29)$ participated.

Baseline anxiety and depression: The Depression Anxiety Stress Scale -21 (DASS21; Lovibond \& Lovibond, 1993) measured baseline anxiety, depression, and stress. Participants indicated the degree to which statements such as "I felt that I was using a lot of nervous energy" had applied to them over the past week. A 4-point Likert scale scored 0-3 (never/not at all; sometimes; often; almost always/most of the time), provided scores between 0 and 63 . The scale has good internal consistency, $\alpha=.93$ (Henry \& Crawford, 2005).

Imagery questionnaire: A computerised imagery questionnaire was developed based on the semi-structured interviews conducted by Homer, et al. (2016) adapted from Hackmann et al. (2000) (appendix 1). The program defined and explained recurrent and intrusive, negative mental imagery and asked participants whether they experience any such imagery based on social interaction (examples such as meeting new people or giving a presentation were given). If so, participants were asked to describe their image and to report its frequency (daily, every few days, weekly, every few weeks, monthly or less than once a month) and occurrence (every day, during negative moods, before leaving the house, before meeting or interacting with others, before big events such as a presentation or interview, and/or at random). Participants then reported whether the image was based on a particular memory and if so, described the memory. Participants were then asked whether the image represented anxiety in a past situation, anxiety of a future situation or a general situation that causes / would cause anxiety. 
Participants who did not experience any recurrent or intrusive imagery, or whose imagery did not represent any anxiety were asked to recall the memory of a social situation in which they felt significantly anxious. All participants then identified the perspective of their image (field or observer) and its sensory modalities (visual, auditory, olfactory, gustatory, tactile and/or physical). Response modes were multiple choice or comment box.

To assess emotionality, participants provided individual scores for the degree of shame, embarrassment, anger, sadness and anxiety elicited by their image on $10 \mathrm{~cm}$ visual analogue scales (VASs) ranging from 0 (not at all) to 10 (extremely).

\section{Procedure}

Participants scoring at least one SD above average on the social anxiety screening measure (SIAS) attended a 45 minute laboratory session. After briefing, participants completed the DASS-21 followed by the imagery questionnaire and then went on to complete several cognitive tasks as part of a larger study not reported here. Finally, participants were asked to recall and visualise an enjoyable social situation, debriefed and given payment or course credit.

\section{Thematic analyses}

Thematic analyses were conducted using the 6 step approach of Braun and Clarke (2006) to address our primary exploratory research question: what do intrusive social anxiety images tend to involve? Initial codes were generated using a theoretical approach: salient cases of theoretical interest based on previous literature were identified within each image. Similar codes were then collated and initial overarching themes were generated and then refined using Patton's (1990) criteria for internal 
homogeneity and external heterogeneity. Themes were then named and defined before subthemes were identified.

\section{Results}

Participants scored a mean of 18.61 on the DASS-21, SD $=8.92$, Cronbach's $\alpha$ $=.879$.

Table 1

Mean SIAS and DASS-21 subscale scores for this sample, clinically socially anxious samples and non-clinical samples. SDs shown in brackets.

\begin{tabular}{|c|c|c|c|c|}
\hline Sample & SIAS & $\begin{array}{l}\text { Depression } \\
\text { subscale }\end{array}$ & $\begin{array}{c}\text { DASS-21 } \\
\text { Anxiety } \\
\text { subscale }\end{array}$ & $\begin{array}{c}\text { Stress } \\
\text { subscale }\end{array}$ \\
\hline $\begin{array}{l}\text { Clinically } \\
\text { socially } \\
\text { anxious } \\
\text { sample }\end{array}$ & $\begin{array}{cc}34.6^{1} & 44.8^{2} \\
(16.4) & (11.6)\end{array}$ & $\begin{array}{l}13.19^{3} \\
(9.28)\end{array}$ & $\begin{array}{c}12.22^{3} \\
(10.20)\end{array}$ & $\begin{array}{c}16.57^{3} \\
(10.91)\end{array}$ \\
\hline $\begin{array}{l}\text { Participants in } \\
\text { this study }\end{array}$ & $\begin{array}{l}40.03 \\
(8.94) \\
\end{array}$ & $\begin{array}{c}6.50 \\
(4.56) \\
\end{array}$ & $\begin{array}{c}4.89 \\
(3.24) \\
\end{array}$ & $\begin{array}{l}7.21 \\
(3.0) \\
\end{array}$ \\
\hline $\begin{array}{l}\text { Non-clinical } \\
\text { sample }\end{array}$ & $\begin{array}{l}18.8^{1} \\
(11.8)\end{array}$ & $\begin{array}{l}2.12^{3} \\
(3.64)\end{array}$ & $\begin{array}{c}1.22^{3} \\
(1.77)\end{array}$ & $\begin{array}{l}3.51^{3} \\
(3.78)\end{array}$ \\
\hline
\end{tabular}


Image characteristics

27 participants $(86.84 \%, \mathrm{~N}=38)$ reported experiencing recurrent, intrusive, anxietyinducing imagery based on social situations. Participants who did not experience any intrusive imagery, or whose imagery did not represent any anxiety, were all able to generate an image based on a time they had experienced anxiety during a social situation. Image characteristics can be seen in table 2. Chi-square tests revealed no significant relationships between gender or clinical status and experience of intrusive anxiety-images or image perspective (all ps > .05). Spearman's rho correlations showed no significant relationships between age or SIAS score and experience of intrusive anxiety-images or image perspective (all ps > .05). 
Table 2

Frequencies of intrusive and generated image characteristics, $N=27$.

\section{Frequency (\% of total)}

\begin{tabular}{|c|c|c|}
\hline Image characteristic & $\begin{array}{c}\text { Intrusive } \\
\text { images } \\
n=27\end{array}$ & $\begin{array}{c}\text { Generated } \\
\text { images } \\
n=11\end{array}$ \\
\hline
\end{tabular}

\section{Frequency of recurrence}

Every day

Every few days

$1(3.70 \%)$

$3(11.11 \%)$

Once a week

$6(22.22 \%)$

Once every few weeks

$6(22.22 \%)$

Once a month

$2(7.41 \%)$

Less than once a month

$5(18.52 \%)$

Other

$4(14.81 \%)$

\section{Occurrence*}

Every day

During negative mood

Before leaving the house

Before meeting / interacting with others

Before a big event (e.g. a speech)

At random times

Other
$1(3.70 \%)$

$9(33.33 \%)$

$2(7.41 \%)$

$19(70.37 \%)$

$18(66.66 \%)$

$9(33.33 \%)$

$1(3.70 \%)$

\section{Based on specific memory}

Yes

$20(74.07 \%)$

$7(25.93 \%)$

$(100 \%)$

$(0 \%)$

\section{Perspective}

Field

$16(59.26 \%) \quad 6(54.54 \%)$

Observer

$11(40.74 \%) \quad 5(45.45 \%)$

\section{Modality*}

Visual

Auditory

Olfactory

Gustatory

Tactile

Somatic

\begin{tabular}{cc}
$25(92.59 \%)$ & $11(100 \%)$ \\
$21(77.77 \%)$ & $9(81.81 \%)$ \\
$6(22.22 \%)$ & $3(27.27 \%)$ \\
$4(14.81 \%)$ & $3(27.27 \%)$ \\
$4(14.81 \%)$ & $2(18.18 \%)$ \\
$24(88.88 \%)$ & $10(90.90 \%)$ \\
\hline
\end{tabular}




\section{Emotionality*}

Shame

Embarrassment

Anger

Sadness

Anxiety

*Participants could select more than one option

\section{Mean (SD)}

$4.04(2.65) \quad 2.45(2.94)$

$7.33(2.11) \quad 4.00(3.16)$

$4.63(2.82) \quad 2.55(3.17)$

$5.96(2.39) \quad 4.73(3.50)$

$7.78(2.21) \quad 5.64(3.35)$

An independent samples $t$ test revealed higher overall DASS-21 scores for participants who experienced intrusive anxiety-images than those who did not $t(32.12)=2.10, p=.044$ (equal variances not assumed). A Spearman's rho correlation revealed that for participants who experienced intrusive imagery, DASS21 scores positively correlated with the frequency of intrusions, $r_{s}=.540, p$ (twotailed) $=.008$ (figure 1). Independent samples $t$ tests showed that scores on the stress subscale did not differ between participants who experienced intrusive imagery $(M=7.33, S D=3.35)$ and those who did not $(M=6.91, S D=1.97), t(36)$ $=.39, p=.698$, nor did scores on the depression subscale $(\mathrm{M}=7.15, \mathrm{SD}=4.86$ and $M=4.91, S D=3.42$, respectively), $t(36)=1.39, p=.173$. However, participants who experienced intrusive imagery scored significantly higher on the anxiety subscale ( $M$ $=5.63, \mathrm{SD}=3.27)$ than those who $\operatorname{did} \operatorname{not}(\mathrm{M}=3.09, \mathrm{SD}=2.47), t(36)=2.31, p$ $=.027$.

Descriptive statistics showed higher emotionality scores for intrusive images than for generated images (table 2) and independent samples $t$ tests confirmed higher levels of embarrassment, $t(13.79)=-3.22, p=.006$; anger, $t(36)=-2.00, p=.054$; and anxiety, $t(36)=-2.32, p=.026$ in intrusive images. However, a Spearman's rho 
correlation revealed that individual emotionality scores did not significantly increase with the frequency of intrusions (all $p s>.05$, two-tailed).

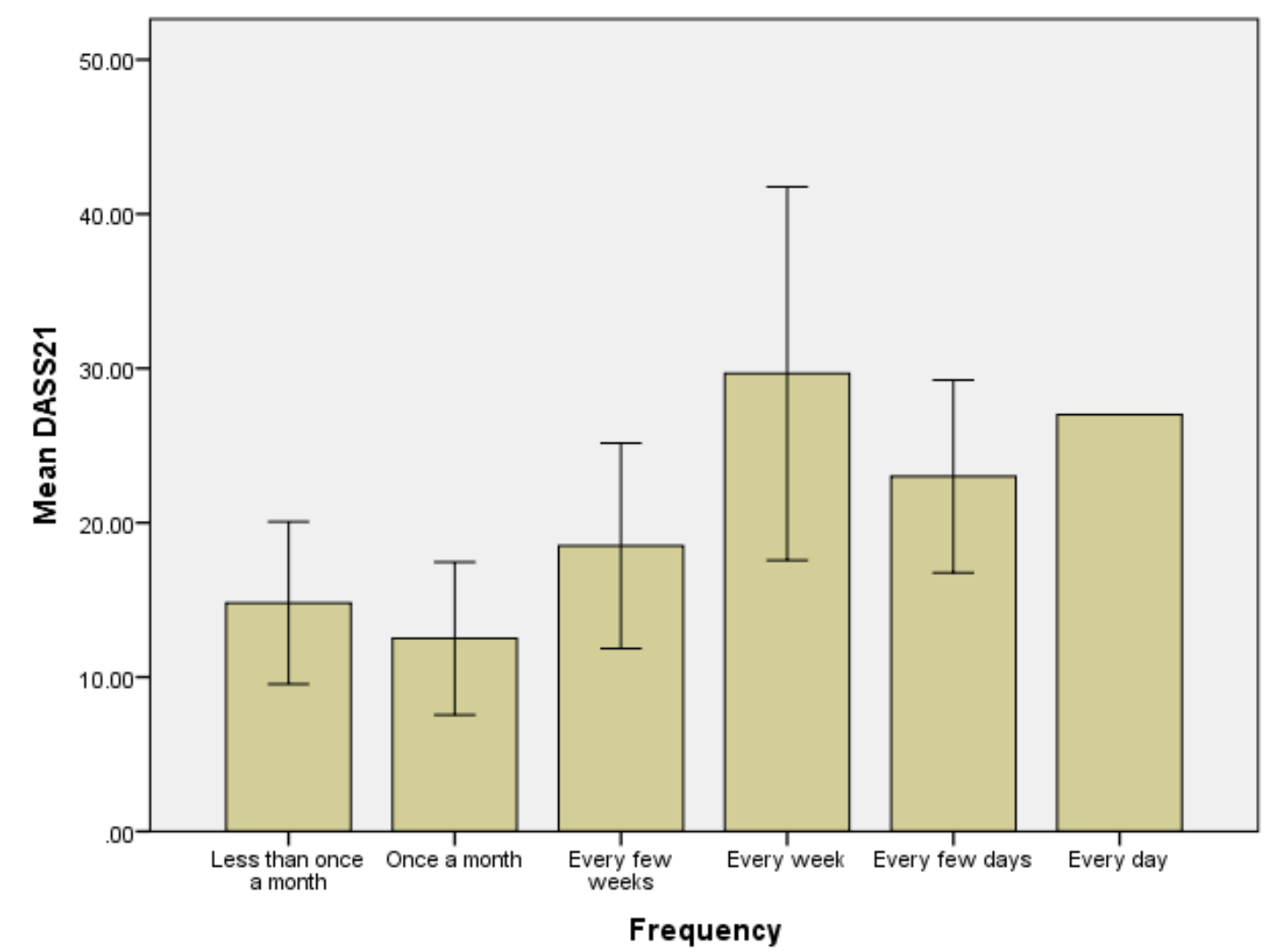

Fig. 1: DASS-21 scores by frequency of image intrusions (Mean +/- SD).

\section{Qualitative analysis}

An essentialist / realist approach was used to generate semantic themes pertaining to individual meaning and phenomenology for both intrusive and generated images. Initial ideas for categorisation included the type of image (e.g. flashback, flashforward or self-image), and the focus of the image (i.e. self, others or self and others). Following the approach described by Braun and Clarke (2006), both assessors determined that the best method for categorisation was the root cause or 
main source of anxiety within each image and full agreement on theme and subtheme configuration was reached. Each image belongs to only one theme and theme prevalence (number of images belonging to each theme) is shown in brackets.

Intrusive Images

Theme 1: Interacting with others (14 images)

14 images focussed on interacting with other people, usually involving others negatively reacting to something they had said or done.

\section{1: Negative reactions from others (6 images)}

Participant 5: "On a number of occasions these memories come into my head. I go red very easily for a number of reasons and I am very self-conscious of it. In fresher's week when I was meeting my flatmates for the first time... they were paying specific attention to it, which obviously made it worse, and I didn't really know what to do, and I felt very panicky."

Participant 17: "I picture myself being rejected by people."

\section{2: Confrontation (5 images)}

Participant 25: "I have several [intrusive images], such as remembering arguments with my parents which got very out of hand."

Participant 22: "After meeting a new person who is living with me next year I had a bad mental image that we had an argument and she did not like me. I was then worried that this could happen." 


\subsection{Meeting new people (1 image)}

Participant 37: Whenever I have to talk in front of new people I remember when I went to a new school and struggled to make friends because of my shyness, the feeling of loneliness reappears whenever I meet new people and I think that we won't get along."

\subsection{General (2 images)}

Participant 3: "Often get the thought of feeling anxious when I am in public surrounded by lots of people, and I remember having previous panic attacks which cause me to feel nervous unnecessarily."

Participant 14: "Thinking people were waving at me when in fact they were waving at someone else."

Theme 2: Anxiety symptoms (8 images)

Eight images focussed on the experience of anxiety symptoms such as blushing, shaking or stuttering either in general or during public speaking.

\subsection{Anxiety symptoms during public speaking (6 images)}

Participant 9: "Doing presentations and feeling myself getting hot, stumbling over words and not being able to give eye contact."

Participant 11: "Stood in front of tutorial group, getting flustered with nerves and not knowing what to say." 
2.2 General (2 images)

Participant 36: "Find myself going red due to embarrassment."

Participant 29: "Going red and feeling flushed."

Theme 3: Performance anxiety (3 images)

Three images involved anxiety during performances other than public speaking, and focussed on the performance itself rather than resultant anxiety symptoms.

Participant 31: "Going to collect an award in assembly in school and tripping while walking up the stairs to the stage, this gets triggered when knowing I have to stand in front of people to get something or to talk."

Participant 19: "When I am revising / doing work / taking an exam I usually remember when I have not done well before which makes me panic that it will happen again."

Theme 4: Negative self-evaluation (2 images)

Two images focussed on negative self-evaluation characterised by upward social comparison or self-focussed disgust and embarrassment.

Participant 30: "Feeling of not being as intelligent / attractive as the person I'm talking to."

Participant 23: "The image would usually involve me saying or performing an act that I look back upon which embarrassment or disgust at myself for acting like that." 
Generated images

Theme 1: Public Speaking (7 images)

The majority of generated images focussed on public speaking either in general or with specific focus on anxiety symptoms or social comparison.

\subsection{General (4 images)}

Participant 6: "Gave a presentation to a small group during first year of degree. Felt nervous beforehand, not so nervous during."

Participant 38: “...I was asked to give a presentation about myself as soon as I got there, making me feel anxious."

\section{2: Upward social comparison (2 images)}

Participant 24: "When I had to give my first presentation in front of my tutor group at university I felt that everyone in the room had more experience than me in the area and that my work was not up to the same standard as everyone else's. I didn't want to do my presentation, I felt my stomach tying into a knot. I felt that everyone was going to think that my work is bad and I didn't want to stand up and present in front of the group."

Participant 8: “...I had to give a presentation on a topic of my choice for 10 minutes with people I was unfamiliar with. I was chosen to go second after a really good presentation so was feeling even more nervous than I already was! My voice started to quiver and my legs turned to jelly at the beginning of my presentation. However, once the initial fear faded a little, I was able to deliver a presentation that wasn't so bad." 


\section{3: Anxiety symptoms (1 image)}

Participant 2: "When I had to do a speech in a public speaking competition I felt my heart beat fast as I walked to the podium, my stomach felt very funny, my voice was very shaky at the beginning of the speech but I became more relaxed as I began to speak."

\section{Theme 2: Meeting new people (3 images)}

3 images described anticipatory anxiety in advance of meeting or interacting with people they have not met before.

Participant 1: "I get anxious on meeting new people... and not knowing what they look like."

Participant 15: "Speaking with anyone I don't know at a party or other informal social moment. I have nothing to say, a blank mind, a film of sweat all over, darting eyes, fumbling limbs and a desire never to do anything remotely similar ever again. It's best for everyone if I don't."

Theme 3: Unwanted attention (1 image)

Anxiety in this final image stems from unwanted attention from a stranger, rather than meeting new people in general.

Participant 35: "Meeting a stranger who was trying to show interest in me in spite of the fact that he was married with a kid." 


\section{Discussion}

As expected, and in keeping with theoretical models (Clark \& Wells, 1995; Hofmann, 2007; Rapee \& Heimberg, 1997) and previous research (Hackmann et al., 1998; Hackmann et al., 2000), the majority of participants experienced recurrent, intrusive anxiety-images based on social interaction. This provides further evidence of the pervasiveness of intrusive imagery in social anxiety (Hackmann et al., 1998; 2000; Hirsch \& Holmes, 2007) and extends previous clinical findings to a sub-clinical sample. Most images were experienced at least fortnightly and usually before meeting or interacting with others, followed by before a 'big event' such as a speech or presentation, followed by 'at random times', and then during negative moods.

Common intrusive image themes included negative reactions from others and experiencing anxiety symptoms, which are highly comparable to themes identified by Hackmann et al. (2000). Novel themes include performance anxiety (without reference to anxiety symptoms), confrontation and meeting new people. Generated image themes generally reflected intrusive image themes but were slightly less diverse: intrusive images were organised into a greater number of themes and subthemes and sometimes represented general self-images (e.g. participants 26 and 39) or flashforwards (e.g. participant 22) more so than memories. Although most of the intrusive images (74\%) were based on episodic memory, intrusive prospective imagery represents an emerging field of research (e.g, Deeprose \& Holmes, 2010) which may be particularly relevant to social anxiety.

Physical and auditory image components were almost as frequent as visual components for both intrusive and generated images. The prevalence of bodily sensations supports the proposed importance of physiological anxiety symptoms in 
models of social anxiety (Clark \& Wells, 1995; Hofmann, 2007; Rapee \& Heimberg, 1997), but may be underexplored within the imagery literature. Interestingly, several participants also reported olfactory, gustatory and tactile elements.

In opposition to previous research (Hackmann et al., 1998; Coles et al., 2001; Wells et al., 1998; Wells \& Papageorgiou, 1999) and models (Clark \& Wells, 1995; Hofmann, 2007; Rapee \& Heimberg, 1997) but in accord with Moscovitch et al. (2011; also Homer et al., 2016), the field perspective was as common (if not more so) than the observer perspective. This discrepancy may reflect intrinsic differences between clinical samples and the sub-clinical sample used here. It is possible that the idiosyncratic core fear is reflected in the perspective or focus of the imagery (anxiety centred either on oneself or on other people), though this could not be investigated from the current results. Future research should seek to investigate relationships between image perspective and other indices, such as associated beliefs and core fears.

Participants who experienced intrusive anxiety-images had higher overall DASS-21 scores and higher anxiety subscale scores, but not depression or stress subscale scores. Further research should seek to map the relative contributions of depression, anxiety and stress to intrusive social imagery. Overall DASS-21 scores increased with the frequency of negative image intrusions, mirroring findings in depression showing an association between severity and the frequency of negative memory intrusions (Brewin, Watson, McCarthy, Hyman \& Dayson, 1998; Kuyken \& Brewin, 1994). Together, these findings suggest a dose-response relationship between the frequency of intrusions and extent of psychopathology, though causality has yet to be demonstrated. 
Unsurprisingly, intrusive images were associated with higher levels of negative emotionality (specifically anger, embarrassment and anxiety) than generated images. However, individual emotionality scores did not increase with the frequency of intrusions as DASS-21 scores did. Though conclusions regarding causality cannot be drawn from these results, a possible explanation for this finding is that the level of distress experienced by the individual influences the frequency of intrusions more so than the emotionality of the image itself, at least in terms of image-related anxiety, shame, embarrassment, anger, and sadness. Future experimental work should seek to test this hypothesis.

Differences between intrusive and generated imagery have several implications for future theoretical and applied work. By their very nature, intrusive images are representative of the general phenomenology and possible maintenance mechanisms of social anxiety (e.g. Hirsch et al., 2003; 2004; Hulme et al., 2012), indicating that they may be a beneficial treatment target. However, higher levels of emotionality suggest that they may be more robust to intervention than less emotional generated images. Experimental paradigms that typically use generated images or negative memories may not be wholly generalisable to socially anxious individuals who regularly experience intrusive images due to the inherent differences suggested by these results. Future research should therefore distinguish between intrusive and generated images. These findings can also provide a reference point for existing and future experimental imagery research, which does not typically analyse or report image content or phenomenology. Though the study used a subclinical sample, regular intrusions of distressing imagery arguably warrant subclinical, ad-hoc mediation such as self-help or computerised interventions. Images could be any combination of sensory modalities which would imply that interventions 
targeting this imagery should tailor their approach to the idiosyncratic phenomenology of the problematic image.

The study used a computerised image questionnaire rather than a semi-structured interview to investigate the imagery experienced by participants. Though imagery can be difficult to elicit, the primary purpose of the experiment was to assess imagery experienced regularly and intrusively by participants which, by definition, is salient and accessible. The computerised interview therefore had the added benefits of increased standardisation and minimal experimenter input, meaning that the images were a valid representation of the participants' experiences reported in their own words. Future replications should ask participants to visualise their image before reporting on it to minimise the impact of verbal processing on the memory (e.g. Stokes \& Hirsch, 2010), and account for participants who may experience more than one intrusive image. Despite the images being specific to social situations, it is possible that depression and other forms of anxiety contributed to the imagery, and so future research should control for differential effects of depression and anxiety on intrusive social imagery. The sample comprised sub-clinical but above average socially anxious undergraduate students; a larger sample including a non-anxious group and clinically socially anxious group would improve generalisability and facilitate identification of between-group phenomenological differences in negative imagery to further elucidate the aetiological and maintenance mechanisms underlying social anxiety. 
Conclusions

Recurrent and distressing mental imagery usually based on autobiographical memory is prevalent even in sub-clinical socially anxious samples. Images were varied and idiosyncratic in their content and sensory modalities, and field perspective images were at least as common as observer perspective images. Intrusive images were more emotional than images generated during the study and more frequent intrusions were associated with higher levels of distress, indicating that intrusive imagery may be phenomenologically unique, and therefore different to imagery generated voluntarily, (e.g. for use in experimental studies).

\section{Acknowledgments}

The authors gratefully acknowledge $\mathrm{XXXXX}$ for programming the computer software necessary for the study and XXXXX for assistance with data collection.

Conflict of Interest: $\mathrm{XXXXX}$ and $\mathrm{XXXXX}$ have no conflict of interest with regards to this publication.

Financial Support: This research received no specific grant from any funding agency, commercial or not-for-profit sectors.

Ethical approval: The authors assert that all procedures contributing to this work comply with the ethical standards of the relevant national and institutional committees on human experimentation and with the Helsinki Declaration of 1975 , and its most recent revision. This work was approved by the University of Plymouth ethics committee. 


\section{References}

Antony, M. M., Bieling, P. J., Cox, B. J., Enns, M. W., \& Swinson, R. P. (1998).

Psychometric properties of the 42 -item and 21-item versions of the

Depression Anxiety Stress Scales in clinical groups and a community sample. Psychological assessment, 10(2), 176.

Antony, M. M., Coons, M. J., McCabe, R. E., Ashbaugh, A., \& Swinson, R. P. (2006). Psychometric properties of the social phobia inventory: Further evaluation. Behaviour research and therapy, 44(8), 1177-1185.

Braun, V., \& Clarke, V. (2006). Using thematic analysis in psychology. Qualitative Research in Psychology, 3(2), 77-101.

Brewin, C. R., \& Holmes, E. A. (2003). Psychological theories of posttraumatic stress disorder. Clinical psychology review, 23(3), 339-376.

Brewin, C. R., Watson, M., McCarthy, S., Hyman, P., \& Dayson, D. (1998). Intrusive memories and depression in cancer patients. Behaviour research and therapy, 36(12), 1131-1142.

Clark, D. M., \& Wells, A. (1995). A cognitive model of social phobia. In R. Heimberg, M. R. Liebowitz, D. A Hope \& F. R. Schneier (Eds.). Social phobia: Diagnosis, assessment and treatment. The Guildford Press: New York.

Coles, M. E., Turk, C. L., Heimberg, R. G., \& Fresco, D. M. (2001). Effects of varying levels of anxiety within social situations: Relationship to memory perspective 
and attributions in social phobia. Behaviour Research and Therapy,39(6), 651665.

Conway, M. A., \& Pleydell-Pearce, C. W. (2000). The construction of autobiographical memories in the self-memory system. Psychological review, 107(2), 261.

Ehlers, A., \& Clark, D. M. (2000). A cognitive model of posttraumatic stress disorder. Behaviour research and therapy, 38(4), 319-345.

Hackmann, A., Clark, D. M., \& McManus, F. (2000). Recurrent images and early memories in social phobia. Behaviour Research and Therapy, 38(6), 601-610.

Hackmann, A., Surawy, C., \& Clark, D. M. (1998). Seeing yourself through others' eyes: A study of spontaneously occurring images in social anxiety disorder. Behavioural and Cognitive Psychotherapy, 26(01), 3-12.

Henry, J. D., \& Crawford, J. R. (2005). The short-form version of the Depression Anxiety Stress Scales (DASS-21): Construct validity and normative data in a large non-clinical sample. British Journal of Clinical Psychology, 44(2), 227-239.

Hirsch, C. R., Clark, D. M., Mathews, A., \& Williams, R. (2003). Self-images play a causal role in social phobia. Behaviour Research and Therapy, 41, 909-921.

Hirsch, C. R., \& Holmes, E. A. (2007). Mental imagery in anxiety disorders. Psychiatry, 6(4), 161-165.

Hirsch, C. R., Mathews, A., Clark, D. M., Williams, R., \& Morrison, J. A. (2006). The causal role of negative imagery in social anxiety: A test in confident public speakers. Journal of Behavior Therapy and Experimental Psychiatry, 37(2), 159-170. 
Hirsch, C., Meynen, T., \& Clark, D. (2004). Negative self-imagery in social anxiety contaminates social interactions. Memory, 12(4), 496-506.

Hofmann, S. G. (2007). Cognitive factors that maintain social anxiety disorder: A comprehensive model and its treatment implications. Cognitive behaviour therapy, 36(4), 193-209.

Homer, S. R., Deeprose, C., \& Andrade, J. (2016). Negative mental imagery in public speaking anxiety: forming cognitive resistance by taxing visuospatial working memory. Journal of Behavior Therapy and Experimental Psychiatry, 50, 77-82.

Hulme, N., Hirsch, C., \& Stopa, L. (2012). Images of the Self and Self-Esteem: Do Positive Self-Images Improve Self-Esteem in Social Anxiety? Cognitive Behaviour Therapy, 41(2), 163-173.

Kearns, M., \& Engelhard, I. M. (2015). Psychophysiological Responsivity to ScriptDriven Imagery: An Exploratory Study of the Effects of Eye Movements on Public Speaking Flashforwards. Frontiers in psychiatry, 6, 115.

Kuyken, W., \& Brewin, C. R. (1994). Intrusive memories of childhood abuse during depressive episodes. Behaviour research and therapy, 32(5), 525-528.

Lee, C. W., \& Cuijpers, P. (2013). A meta-analysis of the contribution of eye movements in processing emotional memories. Journal of Behavior Therapy and Experimental Psychiatry, 44(2), 231-239.

Lovibond, S. H. \& Lovibond, P. F. (1993). Manual for the Depression Anxiety Stress Scales (DASS). Psychology Foundation Monograph. (Available from The Psychology Foundation, Room 1005 Mathews Building, University of New South Wales, NSW 2052, Australia). 
Mattick, R. P., \& Clark, J. C. (1998). Development and validation of measures of social phobia scrutiny fear and social interaction anxiety. Behaviour Research and Therapy, 36(4), 455-470.

Moscovitch,D. A., Gavric, D. L.,Merrifield, C., Bielak, T., \& Moscovitch, M. (2011). Retrieval properties of negative vs. positive mental images and autobiographical memories in social anxiety: Outcomes with a new measure. Behaviour Research and Therapy, 49(8), 505-517.

Nilsson, J. E., Lundh, L. G., \& Viborg, G. (2012). Imagery rescripting of early memories in social anxiety disorder: an experimental study. Behaviour Research and Therapy, 50(6), 387-392.

Ng, A. S., Abbott, M. J., \& Hunt, C. (2014). The effect of self-imagery on symptoms and processes in social anxiety: A systematic review. Clinical psychology review, 34(8), 620-633.

Patton, M. Q. (1990). Qualitative evaluation and research methods (2nd ed.). Newbury Park, CA: Sage.

Rapee, R. M., \& Heimberg, R. G. (1997). A cognitive-behavioral model of anxiety in social phobia. Behaviour Research and Therapy, 35(8), 741-756.

Sansen, L. M., Iffland, B., \& Neuner, F. (2015). The trauma of peer victimization: Psychophysiological and emotional characteristics of memory imagery in subjects with social anxiety disorder. Psychophysiology, 52(1), 107-116.

Stokes, C., \& Hirsch, C. R. (2010). Engaging in imagery versus verbal processing of worry: Impact on negative intrusions in high worriers. Behaviour research and therapy, 48(5), 418-423. 
Wells, A., Clark, D. M., \& Ahmad, S. (1998). How do I look with my mind's eye:

Perspective taking in social phobic imagery. Behaviour Research and Therapy,36(6), 631-634.

Van den Hout, M. A., \& Engelhard, I. M. (2012). How does EMDR work?.Journal of Experimental Psychopathology, 3(5), 724-738.

Wells, A., \& Papageorgiou, C. (1999). The observer perspective: Biased imagery in social phobia, agoraphobia, and blood/injury phobia. Behaviour Research and Therapy, 37(7), 653-658.

Wild, J., Hackmann, A., \& Clark, D. M. (2008). Rescripting early memories linked to negative images in social phobia: A pilot study. Behavior Therapy,39(1), 47-56. 
Appendix 1: Imagery Questionnaire

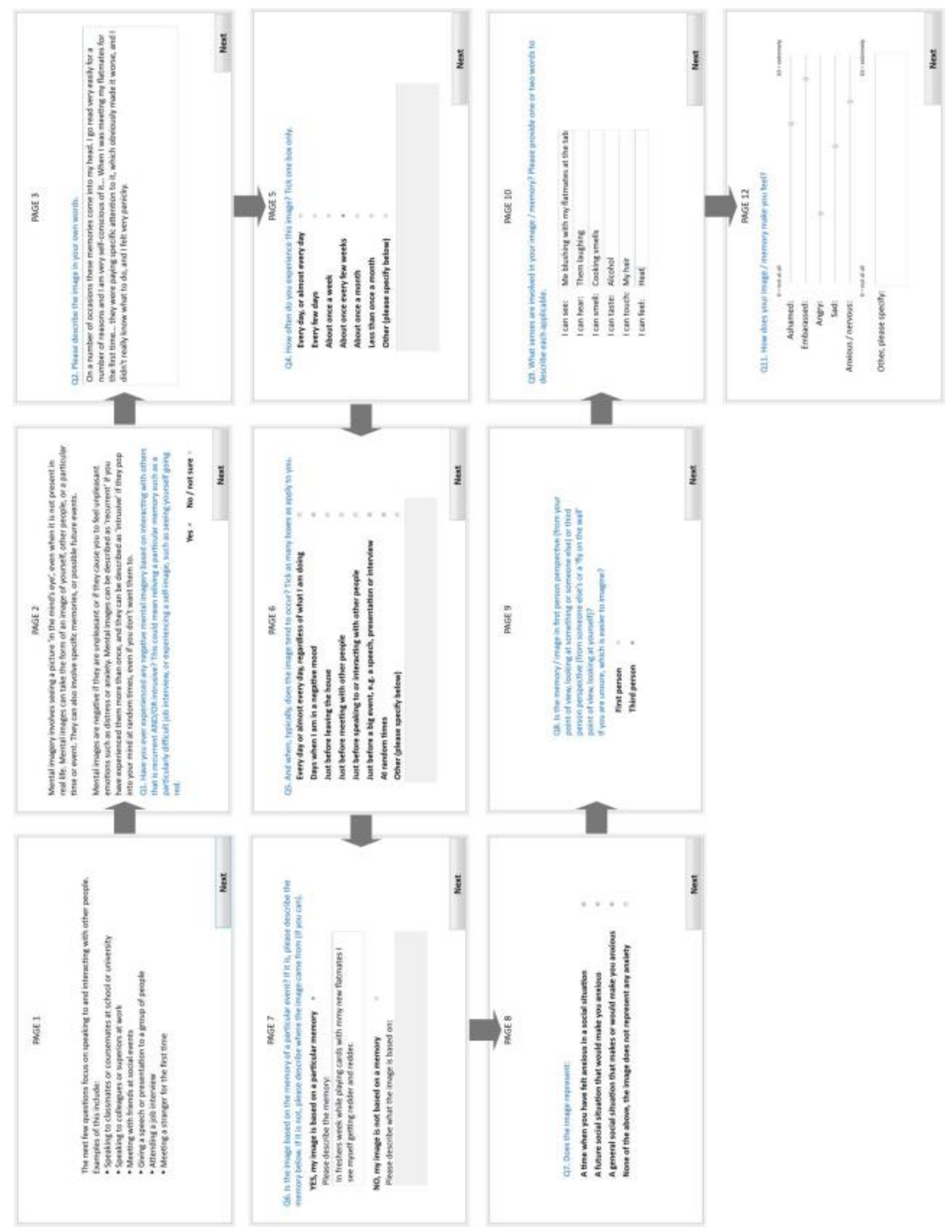

